\title{
Collaborative Networks Approach to Active Ageing
}

\author{
Luis M. Camarinha-Matos \\ Faculty of Sciences and Technology \& UNINOVA \\ Universidade Nova de Lisboa \\ 2829-516 Monte Caparica, Portugal \\ cam@uninova.pt
}

\author{
Hamideh Afsarmanesh \\ Computer Science Department \\ University of Amsterdam \\ Amsterdam, The Netherlands \\ h.Afsarmanesh@uva.nl
}

\author{
Filipa Ferrada \\ UNINOVA \\ Campus de Caparica \\ 2829-516 Monte Caparica, Portugal \\ faf@uninova.pt
}

\begin{abstract}
Collaborative networks involving a variety of stakeholders, e.g. senior professionals, intermediary entities, and beneficiaries have the potential of inducing more effective integration of seniors in the socio-economic system. Based on an extensive analysis of current and emerging organizational models and the analysis of a future scenario, a number of strategic actions are identified to properly adopt a collaborative networks approach to active ageing. Finally, new directions towards the integration of affective computing approaches in a new generation of collaborative systems are suggested.
\end{abstract}

Keywords - collaborative networks, active ageing, emotions management, roadmap

\section{INTRODUCTION}

Many elderly citizens, following retirement, quickly become marginalized and considered as a cost burden rather than a resource, capable of "value creation" in the society. The observed demographic shift combined with some prevalent attitude in Europe that looks at age as a stigma, only worsen the situation. This feeling of exclusion and isolation creates a vacuum in the life of the elderly citizens which in turn affects their health and well being. However, with the improvement of health conditions, many senior citizens could continue giving their contribution to the society after retirement age. An effective transformation of the current situation regarding retirement and the barriers to active ageing in Europe requires the introduction of new approaches and ways to create actively contributing senior professional communities in society [1]. Such approaches should support the elderly citizens with a framework for leveraging their talents and expertise and creating value for their benefit and the benefit of the Europe's economy in general. Furthermore, it is also becoming clear that seniors' knowledge and expertise is essential for the younger workers who have to learn quicker in order to fill the skills gaps that are already noticeable in various areas in the European society.

Permission to make digital or hard copies of all or part of this work for personal or classroom use is granted without fee provided that copies are not made or distributed for profit or commercial advantage and that copies bear this notice and the full citation on the first page. To copy otherwise, to republish, to post on servers or to redistribute to lists, requires prior specific permission and/or a fee. PERVASIVEHEALTH 2010, March 22-25, Munchen, Germany Copyright (C) 2010 ICST 978-963-9799-89-9

DOI 10.4108/ICST.PERVASIVEHEALTH2010.8866
A major obstacle that arises when seniors wish to continue contributing to the society is the lack of proper organizational models capable to support and integrate them adequately. After retirement, professionals miss the organized work context with all its supporting processes and rapidly lose their socioprofessional links. Some of them, with a stronger entrepreneurial spirit, strive to start some free lancing activity, but most have serious difficulty in facing this abrupt transition. The proposed solution requires the interaction of a range of stakeholders that, carrying out different roles, facilitate the bringing together of these professionals and the beneficiaries of the services they can provide. Clearly, the approach for active ageing has to rely on contributions from multiple actors researchers from different fields, decision makers, research policy makers, social care institutions, regional development agencies, etc., and, of course, retired and retiring people themselves, namely through emerging associations of senior professionals.

In recent years we can observe the emergence of a growing number of associations of senior professionals. Although bringing some benefits to their members, namely in the scope of socialization, the current model of these associations may lead to some form of "organized ghettos" for seniors with little inter-generational interaction. In order to guarantee a more holistic integration, the different stakeholders must develop a whole series of business and behavioral models of varied structure, composition and characteristics to allow a variety of alternatives for the integration of senior professionals. Given the relative newness of the recognition of the importance of keeping retired and retiring people integrated into the socioeconomic system and bearing in mind the global tendencies in relation to social security systems, pensions and demography, it is foreseeable that modifications will be necessary with respect to:

- Achieving greater integration of retired and retiring people into the economic and social life as a way to complement 
the decreasing pension levels, as well as a mechanism to cope with the greater healthy life expectancy.

- The role of stakeholders involved in or interested in carrying out mediation between retired and retiring people and the possible beneficiaries of their services. A greater variety of complex relationships among multiple entities needs to be identified and supported.

For this purpose, this paper presents a study of the current and emerging organizational forms and proposes directions for future collaborative organizational models. This work has been developed within the ePAL project [2] which developed a strategic research roadmap focused on innovative collaborative solutions and ensuring a balanced post-retirement life-style.

\section{EXISTING AND EMERGING FORMS}

\section{A. Some baseline findings}

In addition to the traditional initiatives focused only on socialization and entertainment activities for elderly, a number of other organizational forms and mechanisms, already existing or emerging, are focused on providing ways to help seniors remaining professionally active after retirement.

Currently, associations of retired professionals represent an important organizational structure supporting active ageing. Therefore, ePAL conducted a survey on 29 of those associations in Europe and outside Europe in order to get a consolidated view of their practices (Fig.1). The main conclusion is that these organizational forms exist due to the fact that retired people refuse to accept the retirement as the end of a professional life, claiming instead for remaining professionally active. The aim of these associations is essentially to provide assistance to organizations, people and companies that cannot afford to pay remunerated services and organizations located in developing countries, offering basically business consultancy and mentoring services. The majority work on a voluntary basis sustaining themselves through membership fees and/or private or public funding and sponsorship. In terms of ICT, the majority of organizations use old primitive ICT tools; nevertheless they are willing to use new and modern tools to help in their daily activities.

These associations are mostly composed of a "professional elite" i.e. people with a high education and that had high positions in the socio-economic system before retirement. In most cases, these people have reasonable pensions, although varying from region to region, and therefore can afford to do voluntary (unpaid) activities. However, the number of people involved in such mechanisms is not very high.
On the other hand, considering the current difficulties of the social security systems all over Europe, most governments are trying to implement new formula for pensions' calculation which in practice means a reduction of the pensions. In such context, it is foreseeable that more and more people will have fewer resources than needed to satisfy their standards of life.

In addition to these associations of senior professionals, various other mechanisms and practices towards active ageing can be found, including free-lancing, keeping some links with former employer (as the case of jubilee professors), etc. [3], [4], [5]. A number of people also join organizations involved in voluntary social work or clubs that promote socialization activities for elderly, such as time banks [6], [7].

The "individualism" approach, such as free-lancing, corresponds perhaps to the most common approach nowadays, but it presents some barriers [8]. Either when pursuing economic benefits (free lancing) or simple voluntary activities, this approach requires a spirit of initiative (even entrepreneurship skills) that many people do not have or are not willing to exercise at this stage of their lives. Working alone also brings risks, namely related to health conditions. Furthermore, this approach lacks the "socialization" part to compensate for the breaking of social links that were present at the working place before retirement.

As a consequence of the current situation, it can be concluded that some kind of organizational models is needed in order to support the current, emerging and future trends in extending the retired and retiring professional active life. For that it is extremely important to integrate all relevant stakeholders and characterize them accordingly within the scope of active ageing and silver economy.

\section{B. Organizational forms}

New organizational structures are needed in order to address the challenges of the ePAL vision. In this way, departing from the analysis of existing models, some emerging and future forms are suggesting new directions for active ageing.

In order to better understand the current state and potential possibilities, an analysis of the existing organizational models was conducted. Some of the most typical cases are [1]:

Simple Direct Model: In this example the recipient makes direct contact with the senior with the aim of receiving services for a specific project. It is a typical case with freelancers. This model is not scalable and does not cover the socialization needs, being the elderly "left alone". In the particular case of the recipient being the former employer, then some of the social links are maintained.

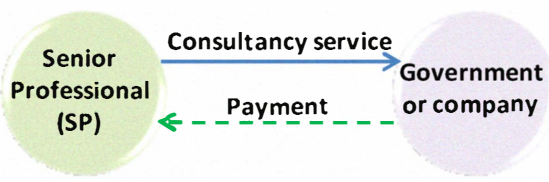

Figure 2. Existing simple model

Intermediation Model 1: In this case the entrepreneur 
typically needs consultancy services in order to get a company project off the ground but cannot afford these services at market rates. The senior professionals association acts as an intermediary and selects the senior that best fits the needs of the entrepreneur from among its members. Typically, besides reimbursement of expenses, the senior professional does not receive remuneration from the entrepreneur although he/she might benefit from the association in other ways (e.g. prestige, experience with new methods, infrastructures, etc.).

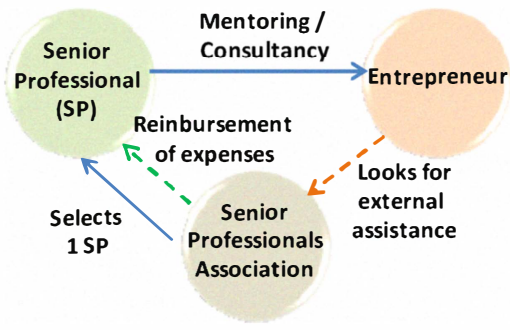

Figure 3. Existing intermediation model 1

Intermediation Model 2: Similarly to the previous case, the entrepreneur asks for consultancy services from the senior professionals association that acts as an intermediary. The association also provides seniors with the methodological approach and infrastructure necessary to carry out the activity. Different from the previous model, in this case the association receives some financial support from the government in addition to the funds raised from its membership fees.

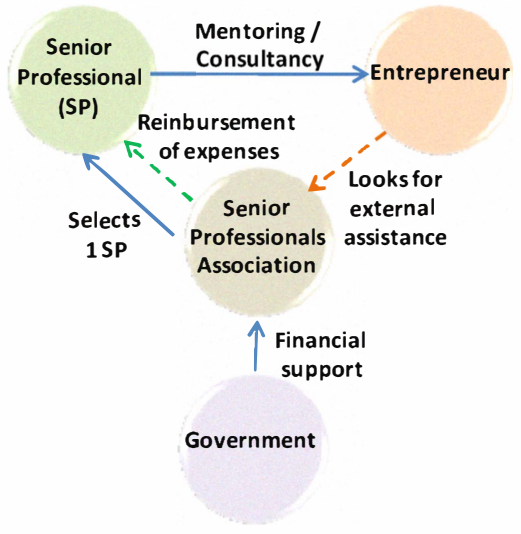

Figure 4. Existing intermediation model 2

Intermediation Model 3: In this case it is assumed that the Governmental Institution has created a consultancy service to micro and start-up companies using senior professionals, financed and supported by Regional Government. Interested companies approach the Governmental Institution to solicit consultancy services. The Governmental Institution, which has an agreement with seniors to provide such services, chooses the senior that better fits the needs of the SME soliciting the service. The chosen senior carries out the mentoring and consultancy task, for which he/she receives some monetary remuneration from the Institution.

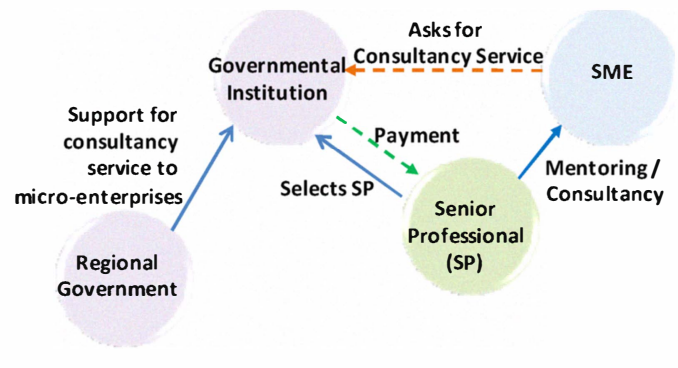

Figure 5. Existing intermediation model 3

Complex case: As in the previous model, it is assumed that the Governmental Institution has created a consultancy program for SMEs, with financial support from the Regional Government. Different from the previous case, the consultancy services are provided through a virtual team supported by an ICT platform, which is provided by some ICT company. The association is in charge of assigning the work to a team of its members and putting them in contact with the recipient in order to provide their consultancy services. For this collaboration the association receives some monetary remuneration. In order to offer the SME a high quality service, the association creates a Team of Senior Professionals specialized in different areas (e.g. marketing, finance, management strategy, etc.) which jointly provide integrated mentoring and consultancy services. Senior professionals receive some reward.

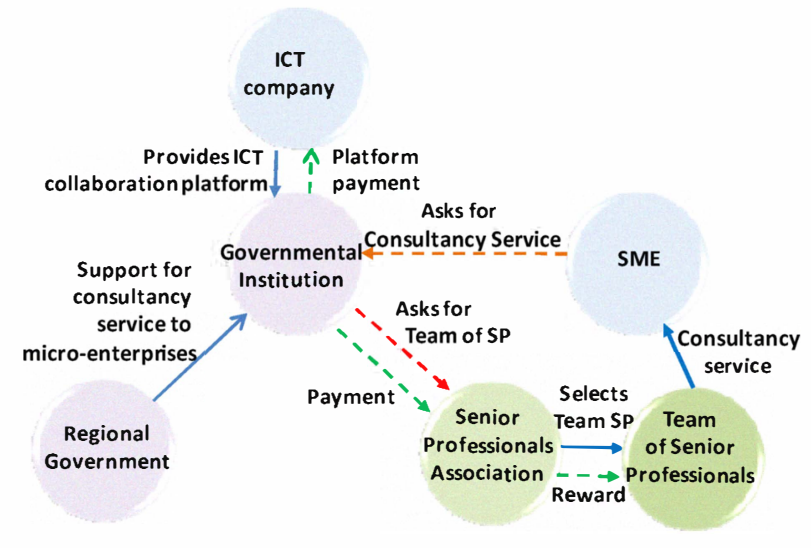

Figure 6. Existing complex model

Currently this case in which tasks are carried out by teams of senior professionals is quite rare. In most cases only one senior is involved in each task.

\section{AN EXAMPLE SCNEARIO}

Before discussing future organizational models and their challenges, let us consider an illustrative scenario (Fig. 7). 


\section{Scenario: Tri-partite company}

José is apprehensive today. In fact he has been worried lately. Everything was different two years ago when he and his friend had this idea for an innovative low consumption air conditioning device and started their FreshAir company. The two engineers soon developed the new equipment thanks to their dedication and enthusiasm. But now they are facing difficulties. They don't know much about marketing or internationalization, although they understand the need to target a global market. Unfortunately they spent all their resources in the start-up phase and now cannot afford to get assistance from one of those big consultancy companies ... Either something happens or they may have to close and fire their employees soon...

Three weeks later...

José and his colleague are having a meeting with Carlos and Ana, two members of the local branch of the Regional Development Agency (RDA). After some initial contacts, Carlos and Ana spent some time in the company making an analysis of its problems and today they are presenting their conclusions. The diagnosis seems logical to José. It is clear that FreshAir needs some coaching and specialized guidance in two crucial areas - focused marketing and internationalization.

But they cannot afford the high costs of such specialized assistance. RDA, an organization funded by the local government and that aims to promote local businesses, made the analysis for free. Unfortunately they do not have the expertise to help in the next phase ...

Guessing the worries passing through José's mind, Ana told them that there is a potential solution. Then she mentioned the ActiveSeniors association ...

Pedro is a retired professional, member of ActiveSeniors. Based on his specific expertise and experience in marketing, he was invited to join a team involving 2 other members of ActiveSeniors with competencies in internationalization and air conditioning. Together with Carlos and Ana from RdA, this team started a temporary collaborative network with people from FreshAir. After 3 months the first results are starting to show up. The ActiveSeniors team not only provided technical assistance and guidance, but also helped FreshAir establish some contacts with a new market in India. Now the business prospects for the young company seem brighter...

Pedro is quite satisfied for having this opportunity to work on a topic where his experience was a real added value. He very much appreciated the diagnosis and preparatory work done by RDA, which allowed him and his senior colleagues to focus on the core issues. Working in a team was a great experience. The small payment Pedro received is also great to complement his pension and give him some better living conditions. FreshAir and RDA could mobilize some resources to pay a small fee to the 3 members of ActiveSeniors, a value much lower than the typical consultancy prices that could never be afforded by FreshAir.

Carlos and Ana got a special recognition from their boss at RDA for being successful in helping a local company and thus creating better economic prospects for the region.

José and his friend re-gained their enthusiasm and they really appreciated the value of this collaboration endeavour with RDA and ActiveSeniors. They certainly plan to keep contact and look forward to again use the amazing pool of expertise \& experience available at ActiveSeniors.

Figure 7. Example scenario
Challenges. The materialization of this scenario poses a number of socio-organizational and technical challenges including:

- Creation of a new collaborative culture at the level of all stakeholders.

- Clear identification and characterization of the roles and possible added-value by each participant in the tri-partite network.

- Development of adequate ICT platforms to support the interactions among the various stakeholders and the work of the collaborative teams.

- Creation of new brokerage and team formation mechanisms and support tools.

- Development of a new legal and tax incentives framework to facilitate this type of collaboration.

- Development of tools for distributed and multi-party project management.

- Clear rules to avoid unfair competition with the normal market actors.

\section{COllaborative Networks CONTRIBUtion}

As implicit in the example scenario, collaboration was vital for this case. On one hand, there is collaboration among different types of organizations - the recipient of the services, the intermediary agency, and the association of senior professionals. On the other hand there is collaboration at the level of the team of senior professionals assigned to this project. It is thus worthwhile to discuss to which extent collaborative networks can lead to new and better approaches in supporting active ageing.

A large variety of collaborative networks involving organizations, people, and even intelligent machines, have emerged in recent years in different application domains [9]. Some of these networks are of a temporary nature, e.g. Virtual organizations / virtual enterprises (VO/VE) or virtual teams (VT), focused on a specific goal and that dissolve after that goal is achieved. Other networks have a longer term purpose and serve mainly the purpose of creating the preparedness conditions to facilitate the dynamic (and fast) creation of goaloriented (temporary) networks in response to business opportunities. These entities play the role of breeding environments in which dynamic VO/VEs or VTs can emerge. That is the case of VO Breeding Environments (VBE) [10], which correspond to an evolution of earlier concepts of industry cluster, industry district or business ecosystem. Another category is the Professional Virtual Community [10] which is an alliance of professional individuals providing an environment to facilitate the agile and fluid formation of virtual teams, similar to what VBE aims to provide for the VO/VEs.

In the context of active ageing, existing associations of senior professionals can benefit from the experience and results in these areas and evolve to a new structure that could be called Communities of Active Senior Professionals (CASPs).

CASP constitutes an association of senior professional individuals that are largely autonomous, geographically distributed, and potentially heterogeneous in terms of their: capabilities, offered capacities, culture, system of values, etc., 
but sharing their main compatible and/or common goals of increasing their active professional life in the society and/or market, through co-working with others in Teams of Senior Professionals (TSP) supported by computer networks. TSP is a collaborative network of individuals configured and established within the CASP in response to opportunities in the society and market that are in need of their wisdom and/or knowledge assets that they can offer, which as a consequence supports the retired professionals remaining professionally active. SP (Senior Professional) is a retired or retiring professional who becomes a member of CASP in order to increase his/her chances of staying active and involved in the socio-economic system, and perhaps also through getting involved in potential TSPs established through the CASP.

It is however important to avoid that a CASP turns into a ghetto for seniors. Their effective involvement in the socioeconomic system needs to consider other stakeholders, namely intermediary entities and the recipients of the services provided by seniors. Some of these entities are also organized in some form of association e.g. associations of SMEs, enterprise incubators or science parks, networks of regional development agencies and associated private (small) consultancy companies. Therefore ePAL proposes a tri-partite network model (Fig. 8) for these collaborative networks.

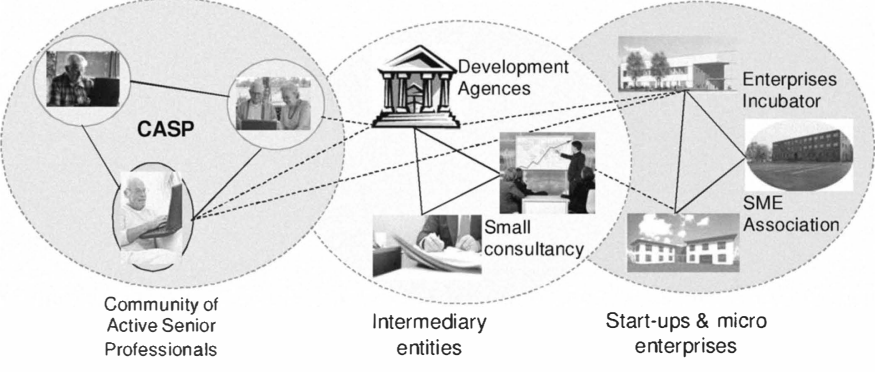

Figure 8. Tri-partite networks

In recent years a considerable amount of tools have been developed in what concerns web-technologies, social networks and collaborative networks (see [9], for instance). Nevertheless new specialized platforms and support tools are needed specifically focused on the needs of seniors and considering the suggested tri-partite model. Examples:

Building collaboration platforms. ICT collaboration platform is a unified electronic platform that shall support synchronous and asynchronous communication within a network through a variety of devices and channels. It offers a set of software components and services that enable actors to find each other and the information they need, and to be able to communicate, interoperate, and work together to achieve common business goals. The core elements of a ICT collaboration platform include messaging (email, calendar scheduling, contacts, etc.), team collaboration (activity coordination, file synchronization, ideas and notes in a wiki, task management, full-text search, etc.), real-time collaboration and communication (e.g., presence, instant messaging, web conferencing, application / desktop sharing, voice, audio and video conferencing), and Social Computing tools (e.g., blog, wiki, tagging, RSS, shared bookmarks).
Effective communities of senior professionals need to be supported by an appropriate ICT collaboration platform. Such platform, besides governance systems of the community, should also provide an advanced management system, and a trust building management system, supported by an affections / emotions -based management system. Furthermore, to realize a proper ICT collaboration platform for senior professionals, further research needs to be performed addressing the following:

(1) Development of advanced collaboration support services, including (virtual) teams' formation and management

(2) Development of affective computing and context aware enriched environments

(3) Formulation of mechanisms and development of systems supporting the establishment of trust among stakeholders

(4) Provision of security and ethical / privacy support.

Building collaboration tools. Collaborative processes in networks, namely through co-working among partners, need to be supported by advanced ICT collaborative tools and services in order to effectively achieve the creation of intended values. As such, strategies established to facilitate the operation of communities of active senior professionals need to be dynamic and aligned with the developments of ICT tools and competitively support them through enhancing time/cost effectiveness of their business climate. Furthermore, services are needed to support networks publicize their name and brokerage brand including the advertising, public relations, customer service efforts, etc. To enable such community members to co-perform their professional activities, ICT services and tools shall facilitate the following aspects that are in need of further research:

(1) Advanced collaboration support services for formation of virtual teams

(2) Advanced services for negotiation and e-contracting in virtual teams

(3) Support for virtual team management and collaborative problem solving

(4) Management of intellectual property and performance

(5) Tools supporting the process of value creation

(6) Advanced marketing and brokerage services

(7) Security and ethical / privacy support services.

Leveraging legacy. Senior professionals' involvement in societal and market activities is not only to provide more economic gains in the market and society but also to transfer the accumulated knowledge and experience to younger generations and other professionals. For the later process to be achieved, considering that the current working environments are mostly ICT-enabled, an ICT environment must be built to support empowering seniors, making them feel useful and needed by the society, as well as easing the process of transferring their knowledge to the intended recipients. As such, innovative mechanisms and tools need to be developed to facilitate the modeling and capturing of talents and skills of senior professionals. Namely, these models can be used to develop services to support acquiring, storing and managing of knowledge assets from senior professionals. Therefore, for these aspects to be realized in communities of active senior 
professionals, further research is needed to address the following topics:

(1) Development of tools supporting inheritance and sharing of user-generated knowledge assets

(2) Design of new networking models providing incentive for involvement of elderly communities in the socioeconomic system.

Furthermore, training and methodological support for using available technologies for content creation need to be developed.

Generating adaptive solutions. Because there are some seniors that may require special training and assistance when dealing with technology, it is necessary to have self-customizable collaboration environments that empower seniors to better use the ICT solutions. Here, several solutions may be developed, such as: self-adaptive interface systems and technology assistance wizards. Therefore, in relation to this topic further research is needed to address the development of "Configure yourself "based philosophy infrastructure, and easily adaptable and customizable user interfaces.

This implies that the technology solution has multiple ways of accomplishing its purpose, and has enough knowledge of its own construction to make effective changes at runtime. Systems built in this way should therefore include functionality for evaluating their behaviour and performance, as well as the ability to re-plan and reconfigure their own operations in order to improve their operation. Self adaptive technology solution should also include a set of components for each major function, along with descriptions of these components, so that components of systems can be selected and scheduled at runtime. It also requires the ability to match changing input/output of sequenced components, and the ability to generate some of this code from the specifications.

Developing conceptual models. There is a lack of comprehensive understanding and a suitable formal conceptual model to represent and support people's professional life cycle and thus it is essential to establish a reference model for the regulation of active ageing and extension of professionals' active life, along with the elaboration of a common ontology for the senior professional communities. Other components are the development of contractual models and business models for the communities of senior professionals. As such, the following research and development of required models need to be further addressed:

(1) Development of conceptual models to support the design and implementation of collaboration support services, including services supporting (virtual) teams' formation and management as well as "user friendly interfaces" for senior professionals

(2) Discovery and management of collaboration ontology that supports a variety of stakeholders in communities of active senior professionals as well as in the configured teams of senior professionals

(3) Design of templates for novel cooperation contracts and agreements, as well as designing models and support environments for the implementation of negotiation processes among actors
(4) Development of models to guide the implementation of advanced marketing and brokerage services

(5) Designing new networking models for elderly communities' involvement with the socio-economic system.

Elaborating behavioural models. The explosive growth in personalized devices, social networks, and novel user interfaces is transforming our daily lives by changing the way we interact with each other and co-exist in society. In case of senior professionals, a deeper understanding of human behaviour is useful to discover the technology needs of the next generation of collaborative networks such as communities of active senior professionals. Namely, it is needed to explore the broad spectrum of discovering, measuring, modelling, and leveraging human patterns and behaviour, in order to develop better ICT infrastructure to support, sustain, and enhance these networks. The evolution of the behavioural patterns and emotional status of senior people when facing a transition from their previous fully active professional life to a retirement phase need to be better understood and properly modelled. Furthermore, the collective patterns and behaviours of involved participants in a network will represent the behaviour and emotional health of the respective network. Some promising areas of further research for this particular purpose is the development of a conceptual base for behavioural modelling, data-mining / machine learning approaches for behavioural patterns discovery, forecasts and simulation methods as well as tools for behavioural analysis, and the models and tools for networks emotional health management. In this direction of research, the following specific topics need to be addressed:

(1) Development of easily adaptable and customizable user interfaces for acquisition of data for behavioural pattern analysis

(2) Development of tools supporting affective computing and context aware enriched environments

(3) Formulation of mechanisms and development of systems supporting the establishment of trust and social bonds among stakeholders

(4) Design of new networking models for elderly communities' involvement with the socio-economic system.

\section{EMOtional State of COllaborative Networks}

This section focuses on the potential role of affective computing in the development of conceptual emotional models and tools supporting an advanced emotional management system.

Emotions constitute a central element for human beings, especially in human interactions. In this way, the study of their functioning is a prerequisite for the understanding of individual and collective behaviors [11], [12], [13]. In the context of collaborative networks, individual participants, as part of a community, experience emotions not only as a result of directly experiencing events (that evoke their own particular emotions) but also through collaborative interactions and by identifying 
themselves with the collaborative network as a whole. As a consequence, if a collaborative network is seen as a living body (a community) then it is dependent of the intricate interactions between the various participants, so it also develops a (collective) emotion which is influenced by each individual participant's dominant emotions representing, in this way, the emotional state or the emotional climate of the network. In humans if the emotional system fails the body suffers the consequences. Likewise, if the $\mathrm{CN}$ emotional system fails, the $\mathrm{CN}$ will not succeed even if from the organizational and social competencies point of view it is excellent. Thus, the introduction of a proper supervision system to manage the emotional climate of collaborative networks with the intention of maintaining the emotional equilibrium of the community, forecasting and attempting to heal potential conflicts among participants and external communities are important elements for the success of the network.

In the ePAL context, there are a variety of participating stakeholders; each with its own emotions and interacting behaviors, so the implementation of mechanisms to understand the collective emotional state of CASPs, to perceive how emotions influence the performance of both CASPs and their senior participants as well as monitor the emotional equilibrium of the interested parties are needed. For instance, in the scenario of Fig.7 if the ActiveSenior network had such mechanisms implemented it would have helped the RDA members to understand if that network was emotionally stable to embrace the workforce. Furthermore, it could have also helped them and the ActiveSenior planner in the choice of the most emotionally and skilled members to join the temporary TSP. It could also contribute to the emotional well-being of the tri-partite networks, avoiding potential conflicts. One of the advantages of this idealized system is the emotional feedback that participants might bring to the network. In the scenario case, the workforce was a success and Pedro felt really happy at the end, this emotion brings to ActiveSenior strong positive feelings that definitely influence a positive change in the emotional state of the network.

In the previous scenario no conflicts between the involved parties were mentioned. Once we are dealing with humans and their interactions within a social context, it is likely that it will not always produce good, positive feelings or emotions. Sometimes things go on the other way and negative emotions (such as sadness, fear, anger, depression, envy or rage) start to emerge in the networks leading to misunderstandings and conflicts that will affect the emotional state of the collaborative network. In this case the envisioned supervision system should trigger dynamic actions (collaborative self-healing) e.g. generating alerts or suggesting actions to be taken by the network coordinator, in order to reduce the negativism and reestablish the emotional equilibrium of the community.

Taking into consideration the variety of stakeholders that participate in collaborative networks, the quantity of emotion related information within the network can be quite large and also unstructured; therefore there is a need to identify, classify and model emotions properly. In this context, several challenges arise which range from how to identify and model the emotional state of the network to the question if it is possible to recognize physiological symptoms in a $\mathrm{CN}$.
Another challenge relies on what mechanisms should be created to generate positive emotions (laughter, humor, happiness, self-esteem, self-efficacy or optimism). Actually, there is already some research work done in the psychological and technological areas that will help in the development of the emotional supervision system.

Emotions Research: Emotions largely remain an open question for researchers, being a subject that can be considered from several different disciplinary perspectives: biology focusing on emotion via observation of physiological responses [14]; psychoanalysis - exploring the deeply embedded nature of human emotions; psychology - differentiating the three realms of thinking (or cognition), feeling (or affect or emotion) and acting (or behavior). However, until recently most works have focused much more on cognition and behavior that emotion [15]. Researchers find it very difficult to describe what emotions are, even when defining basic and secondary emotions [16].

Collective and group-based Emotions: Collective emotions have been defined in a relatively general way as "emotions that are shared by large numbers of individuals in a certain society" [17]. Group-based emotions are defined as "emotions that are felt by individuals as a result of their membership in a certain group or society" [18]. According to Bar-Tal et al. [19] both concepts suggest that individuals may experience emotions, not necessarily as a response to their personal life events, but also in reaction to collective or societal experiences in which only a part of the group members have taken part. Nevertheless, while the former concept suggests that group members may share the same emotions for a number of different reasons, the latter refers only to emotions that individuals experience as a result of identifying themselves with their fellow group members. However, an accumulation of many group-based emotional responses to a societal event can easily turn into a collective emotion. Work done by de Rivera [20] introduces the concept of emotional atmosphere. Atmosphere refers to emotions that arise when members of a group focus their attention on a specific shot-term event that affects them as a group. More recently, Bar-Tal [21] has suggested the concept of a collective emotional orientation, a concept that refers to the characterizing tendency of a society to express a particular emotion. In this context, these concepts are a starting point to better understand the emotions in groups and in different contexts/environments which will assist in the identification and creation of collaborative network's and participant's emotional models. This will also facilitate the formulation of new definitions for conflict resolution within and outside networks.

Emotional Intelligence: The term was created in 1990 by Salovey and Mayer that described emotional intelligence as "a form of social intelligence that involves the ability to monitor one's own and other's feelings and emotions, to discriminate among them, and to use this information to guide one's thinking and action" [22]. Later on several researchers believe that the role of non-cognitive factors definitely help people to succeed in both life and the workplace [23], [24], [25], [26]. In this way, emotional intelligence can contribute for the development of a system to assist on the selection of proper members of a collaborative network to join a TSP. 
Affective Computing: Affective computing is a young field of research dealing with issues regarding emotions and computers. The main objective is to build computers able to feel and interact with humans, so computers must be able to recognize, understand and express emotions as well as interact with intellectual processes [27]. This area is very promising to future developments on the emotional state of CNs due to the fact that it will be needed input emotional data from the participants.

There are some projects running in this area such as the Collective Emotions in Cyberspace project which is EU funded (www.cyberemotions.eu), focusing on the role of collective emotions in creating, forming and breaking-up communities; or the We Feel Fine, a website that takes the "emotional temperature" of the blogosphere (http://www.wefeelfine.org). The development of advanced collaboration platforms to support active ageing can greatly benefit from the above topics in order to foster a sustainable and balanced integration of senior professionals in the socio-economic system.

\section{CONClusions}

The demographic trends, leading to a growing percentage of senior citizens, the challenge faced by many companies in diverse sectors that are losing core competencies when senior professionals retire, the acceleration of changes at all levels which makes difficult the preservation of traditional skills and competencies, their passing down to the new generations or their smooth integration with new skills, the pressure on the social security systems with the consequent downgrading of the pensions, are just some factors that call for new organizational ways and new support technologies for a more effective integration of senior professionals in socio-economic activities.

Models and tools developed in the collaborative networks area have a good potential here but there is a need for the development of a new technological generation that takes into account the specific needs of senior professionals. Besides a perspective of self-adaptivity/self-configurability, a particularly promising direction for the development of novel collaboration platforms and tools is the inclusion of affective computing elements. As such, a number of strategic development areas have been identified by the ePAL roadmapping project.

\section{ACKNOWLEDGMENT}

This work was funded in part be the European Commission through the ePAL project. The authors also thank the contribution of their partners in the ePAL project.

\section{REFERENCES}

[1] A. Cura, Camarinha-Matos, L. M.; Ferrada, F. "New Organizational Forms to Extend the Professional Active Life", in Proceedings of PRO-VE'09, 7-9 Oct 09, Thessaloniki, Greece, Leveraging knowledge for innovation in Collaborative Networks, Springer, pp. 707-718, 2009.

[2] L. M. Camarinha-Matos and H. Afsarmanesh, "Collaborative mechanisms for a new perspective on active ageing", Proceedings of DEST 2009 $3^{\text {rd }}$ IEEE International Conference on Digital Ecosystems and Technologies, Istanbul, Turkey, 2009.
[3] J. Y. S. Cheng, Z. Mujin and W. Zhiyuan, "A Proactive Strategy for the Aging Population That Capitalizes on the Talents of Older Adults in China", Journal of Applied Gerontology, Vol. 26 No. 5, November 2007, pp 454-471, 2007.

[4] N. Potter and P. Leighton, "Cooperative Active AGE Support Trust". http://ec.europa.eu/information_society/events/ict_bio_2006/docs/concert -meet-projects/cast-w.pdf, 2005.

[5] R. Fornasiero, D. Berdicchia, M. Zambelli, G. Masino, "Methodologies for active ageing in the manufacturing sector", in Proceedings of PROVE'09, 7-9 Oct 09, Thessaloniki, Greece, Leveraging knowledge for innovation in Collaborative Networks, Springer, pp. 733-741, 2009.

[6] Collom, Ed., "Engagement of the Elderly in Time Banking: The Potential for Social Capital Generation in an Aging Society" Paper presented at the annual meeting of the American Sociological Association, Philadelphia, PA, 2005.

[7] L. M. Camarinha-Matos and F. Ferrada, "Supporting a Virtual Community for the Elderly". In: S. Dasgupta (Ed.), Encyclopedia of Virtual Communities and Technologies, pp. 428-433, Idea Group Reference, 2006.

[8] Your Encore - Accelerating innovation through proven experience, http://www.yourencore.com/.

[9] L. M. Camarinha-Matos, H. Afsarmanesh and M. Ollus (Eds.), Methods and tools for Collaborative Networked Organizations, Springer, 2008.

[10] L. M. Camarinha-Matos and H. Afsarmanesh, Collaborative Networks: Reference Modeling, Springer, 2008.

[11] N. H. Frijda, The emotions. Cambridge, UK: Cambridge University Press. 1986.

[12] P. N. Johnson-Laird and K. Oatley, " Basic emotions, rationality and folk theory". Cognition and Emotion, 6, 201-223, 1992.

[13] D. M. Mackie, T. Devos and E. R. Smith, "Intergroup emotions: Explaining offensive actions in an intergroup context". Journal of Personality and Social Psychology, 79, 602-616, 2000.

[14] W. James, "What is an emotion?". Mind, Vol. 9, N. 34, 188-205, (1884).

[15] R. Lazarus, Emotion and adaptation. Oxford: Oxford University Press. 1994.

[16] P. Ekman, "An argument for basic emotions". Cognition and Emotion , 6 (3-4), 169-200, 1992.

[17] W. G. Stephan, and C. W. Stephan, "An integrated threat theory of prejudice". In S. Oskamp (Ed.), Reducing prejudice and discrimination, pp. 225-246. Hillsdale, NJ: Erlbaum, 2000.

[18] E. R. Smith, "Social identity and social emotions: Toward new conceptualization of prejudice". In D. M. Mackie \& D. L. Hamilton (Eds.), Affect, cognition and stereotyping: Interactive processes in group perception, pp. 297-315. San Diego, CA: Academic Press, 1993.

[19] D. Bar-Tal, E.Halperin and J. De Rivera, "Collective emotions in conflict situations: societal implications". Journal of Social Issues, Vol. 63, No.2, pp. 441-460, 2007.

[20] J. de Rivera, "Emotional climate: Social structure and emotional dynamics". In K. T. Strongman (Ed.), International review of studies on emotion, Vol. 2, pp. 199-218. New York: John Wiley, 1992.

[21] D. Bar-Tal, "Why does fear override hope in societies engulfed by intractable conflict, as it does in the Israeli society?", Political Psychology, 22, 601-627, 2001.

[22] P. Salovey, and J. Mayer, "Emotional Intelligence". Imagination, cognition, and personality, 9(3), 185-211, 1990.

[23] D. Goleman, "Working with emotional intelligence". New York: Bantam, 1998.

[24] G. J. Feist and F. Barron, "Emotional Intelligence and academic intelligence in career and life success". Annual Convention of the American Psychological Society, San Francisco, CA, 1996.

[25] J. E. Hunter and R.F. Hunter, "Validity and utility of alternative predictors of job performance". Psychological Bulletin, 76(1), 72-93, 1984.

[26] C. Cherniss, "Emotional Intelligence: What it is and Why it Matters". Annual Meeting of the Society for Industrial and Organizational Psychology, New Orleans, LA, April 15, 2000.

[27] R. Picard, Affective Computing. United States. The MIT Press. 1998. 